destroyed and shipped to eastern markets from points west of Saint Louis, Mo.

"The next spring, when the eggs of the locusts began to hatch out, it was discovered, too late, that there were no birds to devour the insects that were so rapidly growing, and must subsist upon the crops until able to fly to other localities.

"It is safe to estimate that a gill [about 0.12 litre] of young locusts, from one day to two weeks old, will number 1000 . Yet a gill would be a small day's ration for a prairie fowl, or half that amount for a quail. It can readily be seen that these young insects, no larger when first hatched than a grain of rye would soon have been exterminated had that quantity of birds been preserved for the purpose; instead of which, from an apparent necessity, the birds were destroyed and consequently the total crops of the state of Kansas and western Missouri, Nebraska and part of Iowa were also destroyed.

"Is it not time some protection was afforded these feathered friends? B."

\title{
ON A HABIT OF SCOLOPENDRA MORSITANS.
}

BY GEORGE DIMMOCK, CAMBRIDGE, MASS.

The note by Mr. J. W. Freese, on page 290 of the present volume of Psrche, upon the habit observed in a species of Phalangium, or harvest man, of putting a wounded part of its leg to its mouth, reminds me of an analogous habit of Scolopendra morsitans.

Last March, while at Banyuls-sur-mer, in the eastern Pyrenees, I took advantage of the abundance of $S$. morsitans in that region to see what would be the result of combats between that poisonous myriapod and Buthus occitanus, a scorpion not rare in the same region. Without detailing their mode of fighting it suffices to say here that the Scolopendra was usually badly lacerated by the violent strokes of the sting of the Buthus, the latter animal always being victor. After receiving a stroke from the scorpion the myriapod immediately, in fact with apparent haste, began working at the wound with its mouth-parts, seeming to eat the fluids exuded from its body. For a time the legs of the myriapod were paralyzed near the wound, the scor- pion's poison apparently acting on the neighboring nervous centers, but in a few minutes the myriapod recovered the use of its legs, and was only killed after repeated serious tearing of its body by the scorpion's sting.

It is possible that the Scolopendra transfers much of the scorpion's poison from the wounds to its stomach, or even that some curative fluid is poured upon them to neutralize the scorpion's poison, but it seems more likely that the process is one of simple cleaning such as the $S$ colopendra would employ if any extraneous matter was put upon the surface of its body, the pain of the wounds only serving to direct immediate attention to them. The same result would probably follow the application of any irritant upon the Scolopendra, and with less rapidity if any viscid fluid was daubed upon its body. Many mandibulate insects cleanse their limbs with their mouth-parts, and I have often seen Scolopendra use its mouth-parts to clean its antennae, legs, and the surface of its body.

Cambridge, 27 Nov. 1882. 

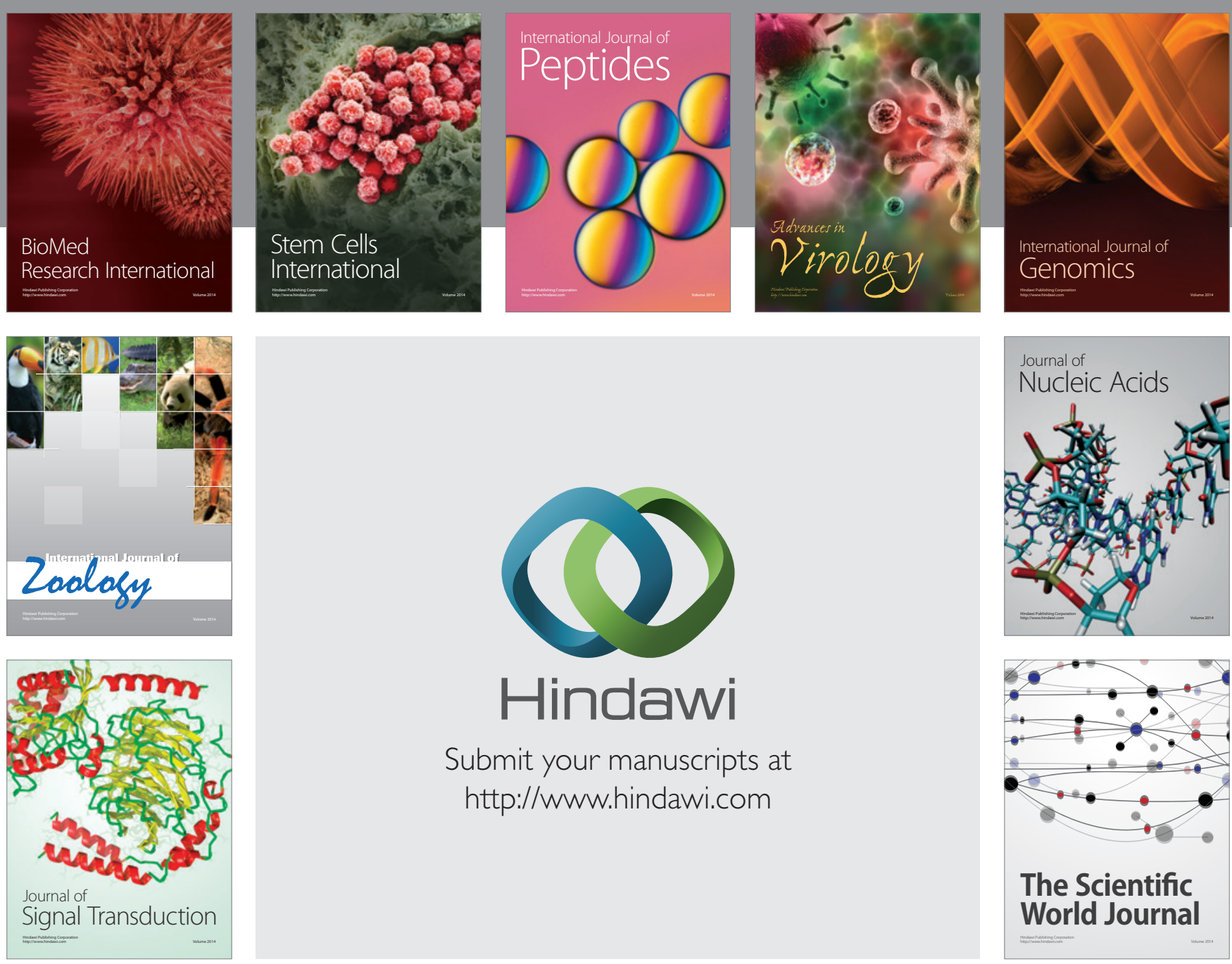

Submit your manuscripts at

http://www.hindawi.com
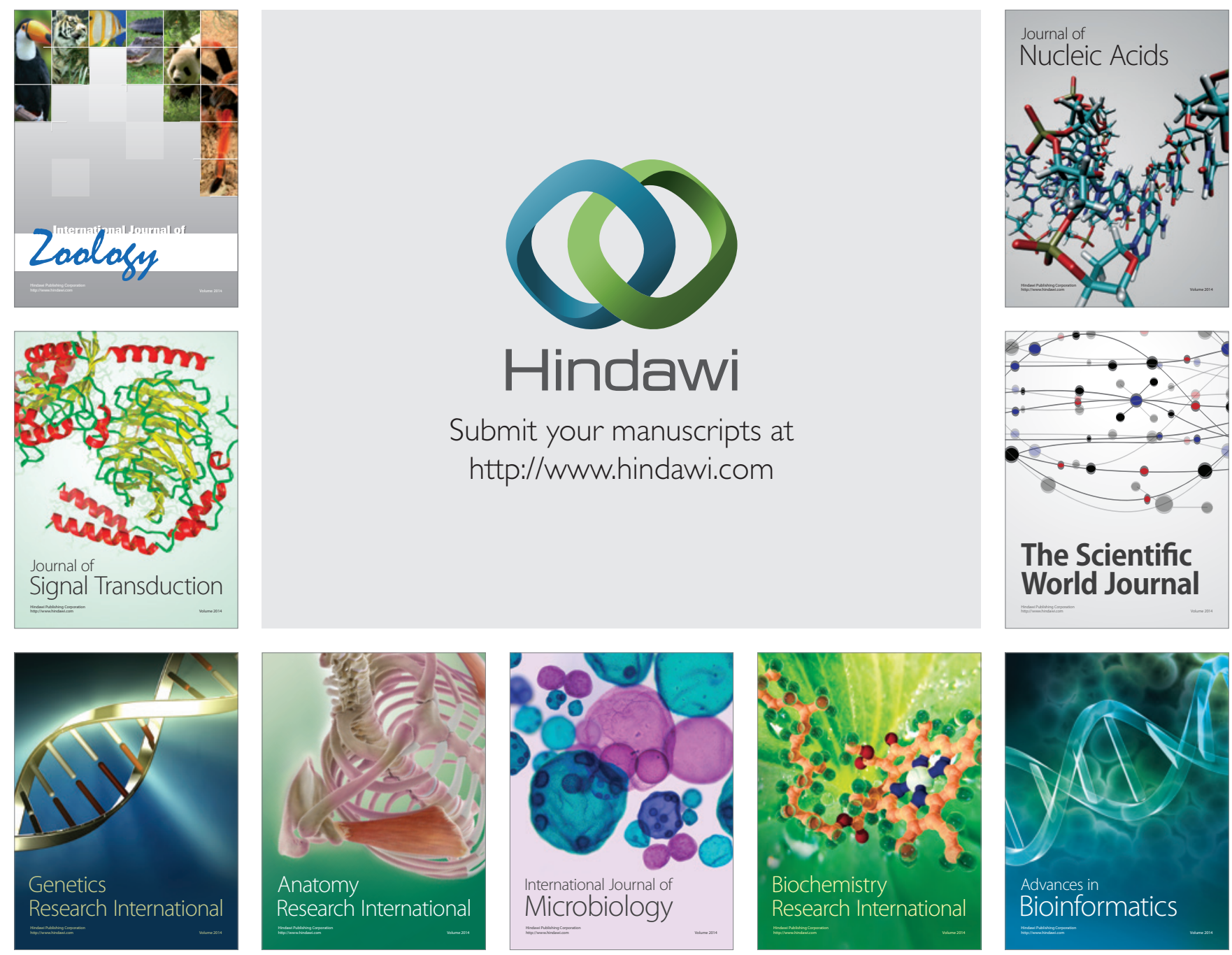

The Scientific World Journal
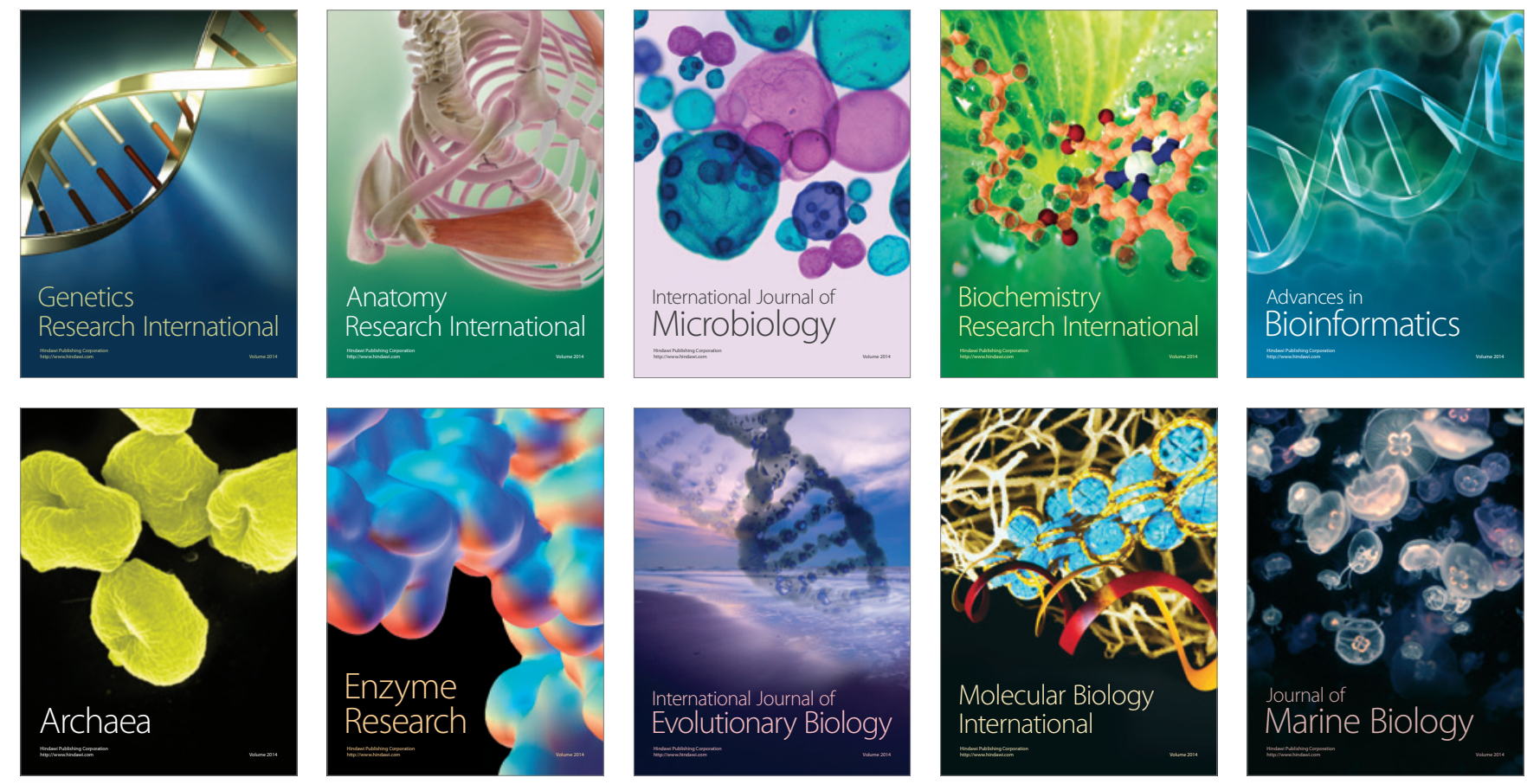